\section{Gategory}

Polymer-

Supported

Synthesis

\section{Key Words}

\section{Evans'} oxazolidinone chiral auxiliaries asymmetric synthesis

solid-phase organic synthesis solid-phase asymmetric alkylation

recovery recycling

T. KOTAKE, Y. HAYASHI, * S. RAJESH, Y. MUKAI, Y. TAKIGUCHI, T. KIMURA, Y. KISO* (KYOTO PHARMACEUTICAL UNIVERSITY, JAPAN)

Design and Synthesis of a New Polymer-Supported Evans-type Oxazolidinone: an Efficient Chiral Auxiliary in the Solid-Phase Asymmetric Alkylation Reactions

Tetrahedron 2005, 61, 3819-3933.

\title{
Evans' Asymmetric Alkylation on Solid Supports
}

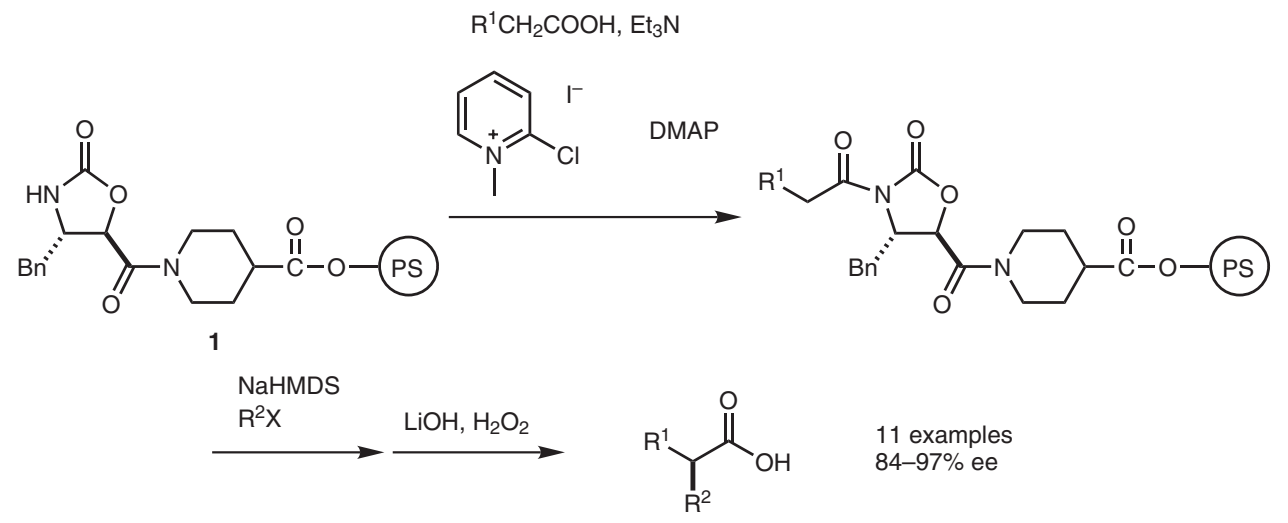

Significance: Highly stereoselective solid-phase asymmetric alkylation reactions were achieved by using Evans-type oxazolidinone $\mathbf{1}$ as a chiral auxiliary. Benzylation at the $\alpha$-position of propionic acid $\left(\mathrm{R}^{1}=\mathrm{CH}_{3}\right)$ gave 2-methyl-3-phenylpropionic acid in $70 \%$ yield with $97 \%$ ee in three steps. The resinsupported chiral auxiliary $\mathbf{1}$ was recovered by simple filtration and was reused three times without any loss of stereoselectivity (1st to 4 th $96 \%$ ee, $R^{1}=B n, R^{2}=$ allyl).
Comment: Solid-phase Evans' asymmetric alkylation reactions were achieved with enantioselectivities that were comparable to the solutionphase alkylation. The selectivity obtained with the immobilized chiral oxazolidinone 1 represents an improvement over the similar auxiliaries so far reported anchoring at the 4-position. 